\title{
Systems of grained materials automated sampling from belt conveyors
}

\author{
Jan Sidor, Marcin Nawrocki \\ AGH University of Science and Technology, Poland
}

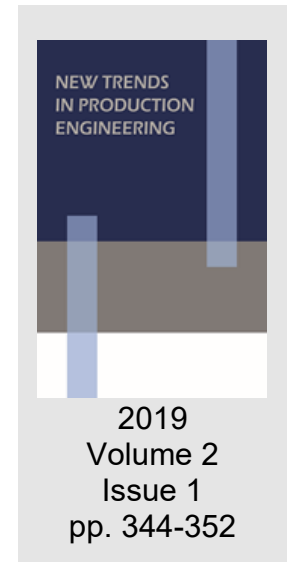

Date of submission to the Editor: 06/2019

Date of acceptance by the Editor: 08/2019

\section{INTRODUCTION}

In technological processes in which there are materials in quantities exceeding tens of $\mathrm{Mg}$, tests of their quality parameters are required on a daily basis. The weight of these samples are in the range of $10-100 \mathrm{~kg}$, and in older plants are taken manually and manually transported to the factory laboratory. The sampling operations are very onerous, especially in open spaces, and the accuracy of their collection is influenced by the work of the personnel. Therefore, to improve working conditions, and in particular, to significantly increase the accuracy of sampled samples, systems for mechanical and automatic sampling were developed. In automatic sampling systems, significantly fewer errors of sampling and significant improvement of operating conditions are achieved. Issues related to automatic sampling systems of grained materials require, in addition to meeting the required accuracy, ensuring long-term stable and safe work. They should be easy to maintain and operate and have stable control and archiving systems for measurement results. In addition, outdoors should work properly under changing weather conditions. These systems can be placed on the conveyor belt routes and take samples directly from the mobile belt, on the discharge point and in a special version for sampling from wagons, prisms, and even truck platforms. The system of automatic collection and preparation of representative (laboratory) samples consists of several devices. These systems have a diversified structure adapted to the requirements of a specific technology in which grained material is used. The most common elements of this system are (M\&W Jawo-Handling, Siebtechnik, Quality Handling Systems and Intersystem):

- device for collecting a sample from a conveyor belt, a discharge point, a wagon, or another place,

- samples transporting device: to a crusher, to samples divider or to the laboratory, 
- one or more samples dividers to prepare a laboratory sample from a general sample,

- transport devices for transporting the representative sample to the laboratory,

- devices for transporting the remaining part of the sample to the pile of the waste (treated as waste) or to the container (standard value material).

In many industries, the operation of collecting a general sample, its transport to the laboratory room and preparation of a laboratory sample is still carried out manually. However, due to the systematic increase in labor costs and the improvement of the conveyor transport operating conditions, as well as the improvement of the working conditions, the work is aimed at replacing in this operation the manual mechanical device controlled automatically.

Most often, samples are taken from a conveyor belt, transporting grained material for dispatch, or for another technological operation. Sampling from the pouring or chute can be implemented practically only during the design of the transport system and is associated with additional costs, whereas the collection of grained material from the conveyor belt can be realized on the used conveyor, which is much easier.

Currently, there is an increase in the requirements for the quality of the product delivered, on the part of recipients, especially customers of solid fuels. These are power plants and combined heat and power plants that, due to the level of $\mathrm{CO}_{2}$ emissions, the amount of electricity and heat generated are seeking to optimize costs. Currently, the majority of coal-fired power plants and a significant part of the combined heat and power plant are equipped with automatic samplers, used for taking fuel samples, tested in the laboratory. Automatic sampling systems are installed as systems for testing the quality of deliveries, and for the settlement of $\mathrm{CO}$ emissions, as well as testing the quality of biomass used by fuel producers. Automatic samplers also become equipment for mining and processing plants of mineral resources.

Therefore, the subject of the work is the problem of systems for automatic collection of representative samples of grained materials with a maximum dimension of about $150 \mathrm{~mm}$ directly from the conveyor belt.

\section{BASIC REQUIREMENTS AND PROCEDURES OF AUTOMATIC SAMPLING SYSTEMS}

When sampling coal and coke, the sampling device should comply with the procedures given in the following standards: ISO 13909-2: 2004, ISO 13909-5: 2005, G-04502, ISO 13909-2 Lot 2: Coal. Sampling from material streams. Devices and sampling systems are subject to certification for compliance with the above standards by GIG or ICHPW.

Detailed guidelines for sampling are given in the study (IOŚ). However, recommendations for the quantity and mass of collected carbon samples were given in (GRC).

The number of $n$ sample units should be taken for testing quality parameters of coal - a coal batch of a given mass. This number depends on a lot of weight 
and the desired overall accuracy of the sample. The minimum requirements are in Table 1.

Table 1 Influence of grained material mass
on the number of primary samples (GRC)
\begin{tabular}{|l|c|}
\hline \multicolumn{1}{|c|}{$\mathbf{0}$} & The number of sampling \\
\hline$<5000$ & 1 \\
\hline $5001-20000$ & 2 \\
\hline $20001-45000$ & 3 \\
\hline $45001-80000$ & 4 \\
\hline $80001-125000$ & 5 \\
\hline $125001-180000$ & 6 \\
\hline $180001-245000$ & 7 \\
\hline
\end{tabular}

Every single sample is taken by a sampler in a number of $n$ samples, where $n$ should be 10 or more. The properties of the coal batch can be determined with general accuracy to the equation (GRC):

$$
d_{w}=\mp 2 \frac{\frac{b_{j}}{n}+b}{u}
$$

where:

$d_{w}-$ required precision of sampling of a single sample, if not specified, take 0.2 , $b_{j}$ - error of a single original sample, if no data is available, 20 should be taken, $b$ - sample preparation error,

$u$ - number of single samples.

If the given accuracy $d_{w}$ - is specified, then the number of samples $\mathrm{n}$ and the number of single (partial) samples $u$ can be determined from the dependences (2) and (3) (GRC).

$$
\begin{gathered}
n=\frac{4 b_{j}}{u d_{w}^{2}-4 b} \\
u=\frac{4\left(b_{j}+n_{1} b\right)}{n_{1} d_{w}^{2}}
\end{gathered}
$$

where:

$n_{1}-$ adopted accuracy of sampling a single sample.

It is recommended (GRC) to round up the value of $n$ and $u$.

The weight of the original sample taken, consisting of individual samples, is determined by three elements:

- the efficiency of the belt conveyor, $\mathrm{Mg} / \mathrm{h}$,

- a scoop collecting a sample from a tape, which should be at least three times bigger than the maximum grain size of the grained material, $\mathrm{mm}$,

- the speed of the taken element [m/s].

The weight of the sample determined exactly should also take into account the conditions of sampling, that is, the rest or movement of the conveyor belt. Table 2 shows the effect of the maximum dimensions of the coal grains on the mass of single samples and in Table 3 an example of the selection of the automatic sampler work parameters. 
Table 2 Effect of coal graining on the mass of a single sample (GRC)

\begin{tabular}{|c|c|}
\hline $\begin{array}{c}\text { Nominal size of the biggest } \\
\text { coal grains, } \mathbf{~ m m}\end{array}$ & $\begin{array}{c}\text { Reference mass } \\
\text { of single samples, } \mathbf{k g}\end{array}$ \\
\hline 300 & 100 \\
\hline 200 & 25 \\
\hline 150 & 15 \\
\hline 125 & 10 \\
\hline 90 & 5 \\
\hline 63 & 3 \\
\hline 45 & 2.0 \\
\hline 31.5 & 1.0 \\
\hline 22.4 & 0.75 \\
\hline 16.0 & 0.50 \\
\hline 11.2 & 0.25 \\
\hline 8.0 & 0.15 \\
\hline
\end{tabular}

Table 3 An example of choosing the parameters of the system for automatic sampling of coal samples (GRC)

\begin{tabular}{|l|l|}
\hline \multicolumn{1}{|c|}{ Material of samples } & \multicolumn{1}{c|}{ Coal } \\
\hline Recommended Norma & ISO 13909 \\
\hline $\begin{array}{l}\text { Location of the sampler - on the conveyor belt } \\
\text { or on the sifting }\end{array}$ & $\begin{array}{l}\text { On the conveyor belt located } \\
\text { horizontally }\end{array}$ \\
\hline $\begin{array}{l}\text { Place of application of the return from } \\
\text { the separated sample }\end{array}$ & $\begin{array}{l}\text { Return to the conveyor belt } \\
\text { located horizontally }\end{array}$ \\
\hline The total mass of coal & $20000 \mathrm{Mg}$ \\
\hline Time of sampling & $8 \mathrm{~h}$ \\
\hline Bulk density of coal & $2200 \mathrm{~kg} / \mathrm{m}^{3}$ \\
\hline The range of maximum dimensions of grains & $50 \div 30 \mathrm{~mm}$ \\
\hline The width of the tape & $1200 \mathrm{~mm}$ \\
\hline The speed of the tape & $1.6 \mathrm{~m} / \mathrm{s}$ \\
\hline Conveyor capacity & $2500 \mathrm{Mg} / \mathrm{h}$ \\
\hline Material of samples & $5 \mathrm{~m}$ \\
\hline \multicolumn{2}{|c|}{ Requirements of the sample preparation for tests } \\
\hline The maximum grain size & $10 \mathrm{~mm}$ \\
\hline Sample weight & $10 \mathrm{~kg}$ \\
\hline
\end{tabular}

\section{SYSTEMATICS OF AUTOMATIC SAMPLING SYSTEMS}

The work (Tomas, Matusiak and Bal, 2010) gives the general systematics of the samplers taking samples from the transport system, i.e. from the conveyor belt and from the dumping or chute.

The main systems division:

- with one sampler,

- with two series sampler,

- with two parallel samplers that take samples from two parallel conveyors as one representative sample into one collective container.

The second division takes into account the construction and additional equipment of the system. These are systems equipped with:

- additional crusher for grain dimensionality reduction,

- samples mixer,

- one or two sample dividers,

- in a conveyor system that performs a function as a sample divider,

- devices for transporting the remaining part of the sample.

The third division takes into account the type, structure and, control system of the automatic sampling system. 


\section{STRUCTURE OF AUTOMATED SAMPLING SYSTEMS FROM A CONVEYOR BELT}

These systems have a structure adapted to the needs of a specific industry using grained material. Depending on the needs, the system is equipped with one or two automatic samplers. In the case of two samplers, these are the initial sampler and the final sampler. In any case, the samplers are the most important devices of the sampling systems.

For automatic control of these systems, autonomous systems are used, which in addition to controlling perform the function of data archiving and their transmission to works control systems or a quality control system.

Most of these types of systems are used to take samples of coal, ores, coke, raw materials for the production of mineral binders and aggregates. The structure, method of work and technical parameters of the sample holders are determined by the type of material to be sampled, its grain size and the conditions for sampling:

- during movement or stationary tape,

- the position of the tape (horizontal, slope to the horizontal),

- the shape of the collection zone (flat, trough-shaped tape),

- the need to maintain unchanged graining, which is especially important when sampling coke.

Examples of two systems of this type, which can be treated as classic, are shown in Figures 1, 2 and 3. The system shown in Figure 1 is intended to take a representative sample of material while preserving its grain composition for final testing, whereas the system shown in Figure 2 has a crusher for initial fragmentation of the sample.

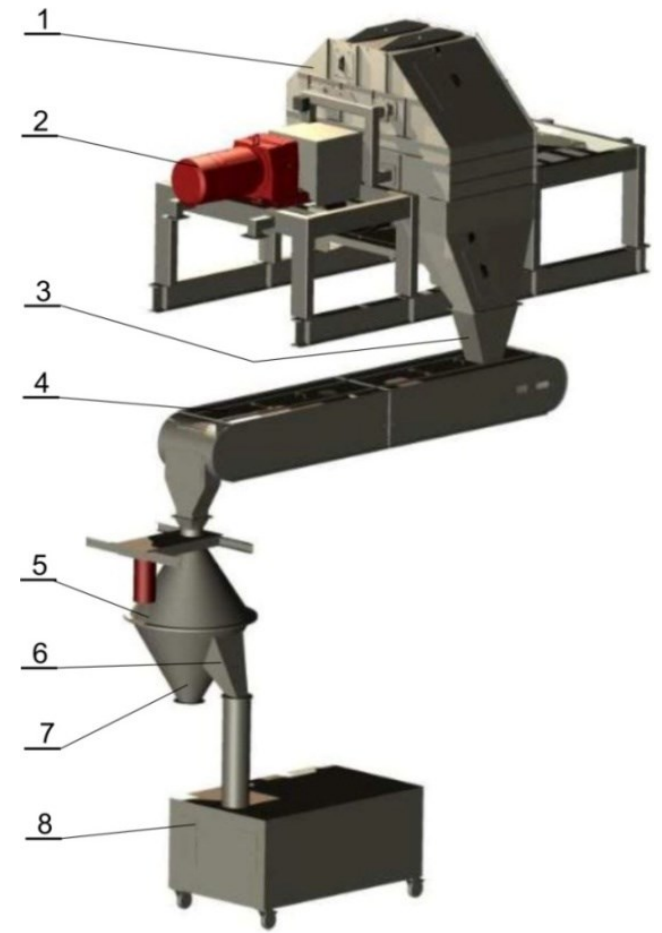

Fig. 1 The sampling system without changing the grain size: 1 - primary sampler, 2 - drive, 3 - feeding chute, 4 - conveyor, 5 - divider, 6 - sample exit, 7 - waste exit, 8 - samples container Source: (M\&W Jawo-Handling) 


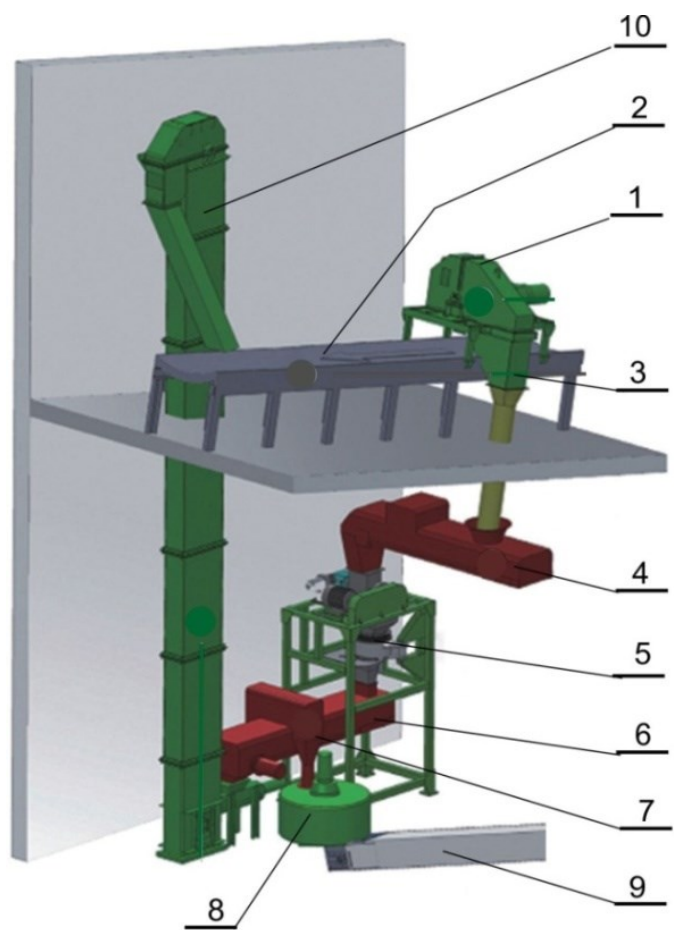

Fig. 2 Sampling system with crusher:

1 - initial sampler, 2 - conveyor, 3 - feeding chute, 4 - conveyor, 5 - crusher, 6 - conveyor, 7 - secondary sampler, 8 - divider, 9 - sample conveyor, 10 - waste conveyor (CKIC)

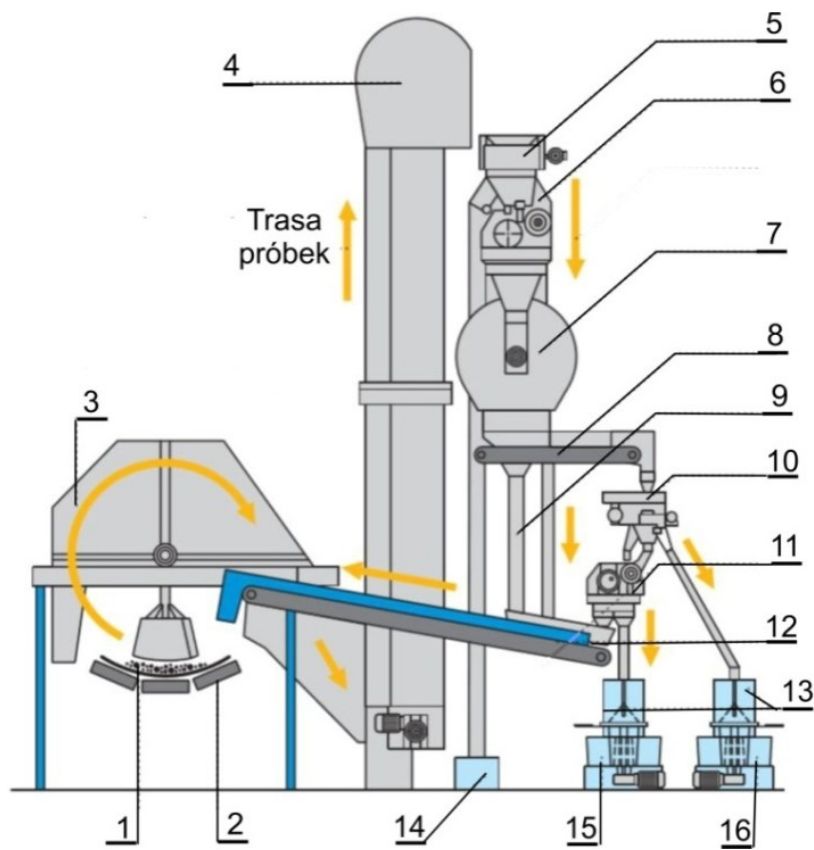

Fig. 3 Sampling system with pre-transport:

1 - sample, 2 - belt conveyor, 3 - sampler, 4 - bucket conveyor, 5 - belt feeder, 6 - hammer crusher, 7 - sample divider, 8 - sample conveyor, 9 - waste, 11 - hammer mill, 12 - waste turn back conveyor, 13 - mixer, 14 - pre-crash samples container, 15 - primary sample container,

Source: (Fourtech)

16 - secondary sample container,

Design solutions for sampling systems from conveyor belts showed at Figures 4,5 and 6. 


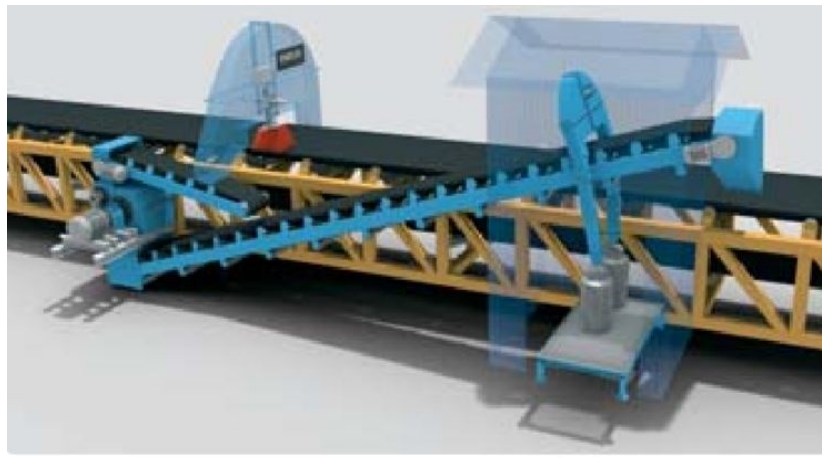

Fig. 4 Sampling system with two samplers and a crusher with a division of the sample into two containers

Source: (Fourtech)

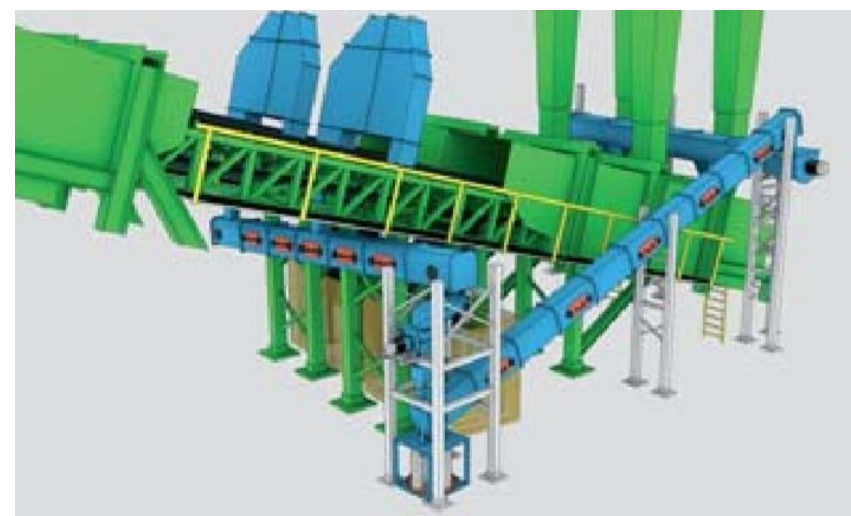

Fig. 5 The system of collecting representative samples simultaneously Source: (Fourtech)

from two conveyors - intended for high-capacity transport systems

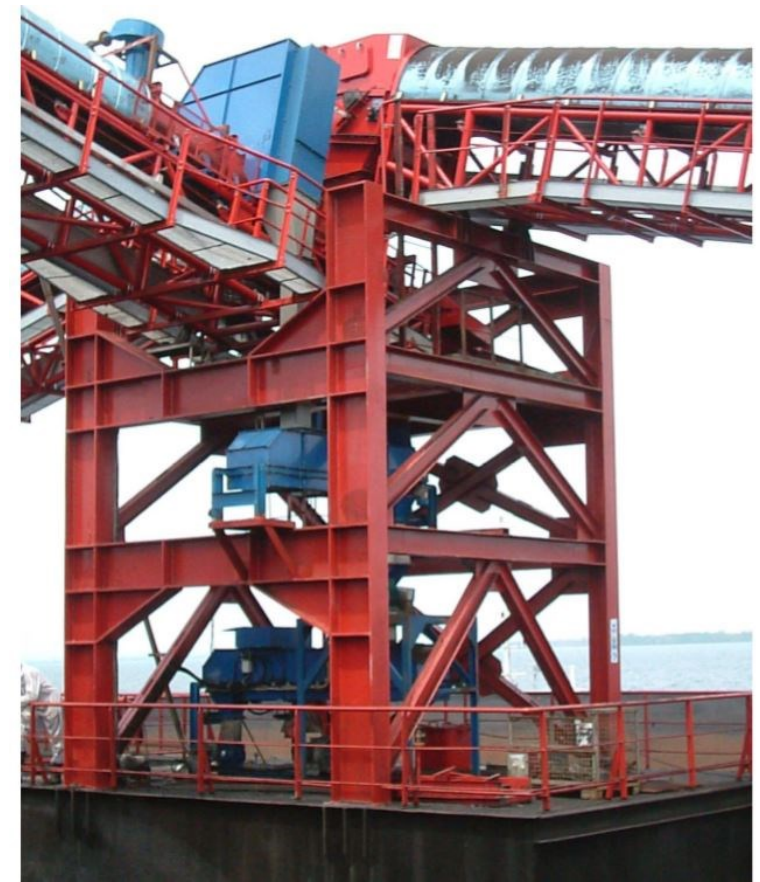

Fig. 6 The sampling system from the conveyor belt located near the dumping Source: (Fourtech)

\section{CONTROL SYSTEMS FOR AUTOMATIC SAMPLING SYSTEMS}

Observing the development of industrial automation, it can be stated that the machine's operational safety is included in the structure and operation of its 
control system. Its correct construction and selection of the appropriate apparatus for the application are very important here. The control system in terms of safety functions should always be designed and made based on the results of the previously carried out risk assessment process required by the directives. Risk assessment, as well as other requirements of directives and standards, may expand the pre-established technological control system.

In this case, the automatic control system provides a programmable sampling of primary samples, which may depend on the weight of the lot, the number of railway cars, the time of collection, as well as the interruptions in the movement of the belt, the lack of material on the belt. Such a system should be composed of at least one control unit (usually a PLC), sensors and drives. The implementation of the control requires information on the status of individual devices and machines, the collection of information on the sampling made and the filling level of the sample tanks, etc. They are stored at a higher level of control.

The advantages of the automatic collection concerning manual consumption:

- repeatability,

- programming,

- material intake from the entire cross-section of the stream,

- an automatic reduction and division of the sample not,

- an automatic reverse of excess material,

- it removes people from working in difficult conditions.

\section{CONCLUSIONS}

Automatic sampling systems have found wide applications in industry. The sampling systems for belt conveyors are presented. Automation of the sample preparation process for laboratory testing requires the use of multiple devices connected in series with the transport system. The implementation of the automation of this process is complex and expensive. As a result, the elimination of human error, an increase in efficiency, sampling certainty, and constant conditions of a collection are obtained.

Most recipients of grained materials have devices capable of controlling the quality of the product received. It is required to monitor the quality of the product offered, both due to maintaining the appropriate quality and the need to document it. The use of automated samplers ensures the repeatability and impartiality of the quality control process.

\section{REFERENCES}

Automatic samplers of coal. Coal Quality Management Systems Solid Fuels And Bulk Materials Sample taking and preparation. WB240E/03.2013 Siebtechnik www.siebtechnik.com

Automatic Sampling Sytems. www.intersystems.netcPty Ltd Sampling Solution Specialists Sampling Systems for Bulk Materials. www.qhs.com.au

HP - Cross belt hammer representative sampling from trough-shaped conveyor belts. M\&W Jawo-Handling. www:m-w.dk

Mechanical sampling. www.fourtech.it 
Rozporządzenie w sprawie monitorowania i raportowania - wytyczne dotyczące pobierania próbek i analizy, (2012). Wyd. IOŚ-PIB, Warszawa

RSS - Representative Sampling System. https://www.grc.pl/en/

Tomas A., Matusiak P., Bal M., (2010): Automatyczne próbobiorniki materiałów sypkich stosowane w przemyśle. Górnictwo i Geoinżynieria. Z. 4/1, s. 271-284

www.ckic.net/products/mechanical-sampler/5e-cyp-cross-belt-sampler.html

\begin{abstract}
.
The collection of representative samples of grained materials is necessary to determine the quality parameters of this material. This operation is carried out in difficult conditions (dustiness, noise, atmospheric precipitation), which is a nuisance to the staff taking samples and adversely affects accuracy. In addition, the quality of representative samples is affected by the care of personnel. Therefore, to ensure a higher quality of sampling operations and to eliminate the work of people in difficult conditions, systems have been developed for the automatic collection of representative samples from conveyor belts. The work gives examples of automatic sampling systems equipped with samplers and other auxiliary devices. The work contains descriptions of construction, classifications, an example of selection and examples of construction solutions for automatic sampling of grained materials.
\end{abstract}

Keywords: grained materials samplers, sample preparing, automated systems 